\title{
Las representaciones sociales del alumnado sobre la crisis. ¿Qué soluciones ofrece el alumnado ante los problemas económicos?*
}

\section{Social representations of students about the crisis. What solutions can offer the pupils facing economic problems?}

\section{Rafael Olmos Vila ${ }^{(1)}$; Neus González Monfort ${ }^{(2)}$ y Joan Pagès Blanch ${ }^{(2)}$}

(1) IES Bernat de Sarrià de Benidorm. (2) Universidad Autónoma de Barcelona

Resumen: Este artículo presenta los resultados de una investigación sobre las representaciones sociales de adolescentes de 16 a 18 años de la actual crisis económica. Estos adolescentes pertenecen a dos grupos de bachillerato de un mismo centro educativo y provienen de contextos socioeconómicos similares, sin embargo uno de los dos cursa las asignaturas de Historia Contemporánea y Economía (Grupo A) y el otro no (Grupo B). Se recopila la información a partir de un cuestionario escrito sobre noticias actuales y de un grupo de discusión sobre el tema. Los resultados muestran la influencia de los medios de comunicación en las respuestas de ambos grupos y una mayor viabilidad de las soluciones propuestas por los estudiantes de Economía e Historia.

Palabras clave: Representaciones sociales, crisis y problemas económicos, pensamiento crítico, pensamiento creativo, solución de problemas.

Abstract: In the following article are reported the results of a research on social representations about the economic crisis of adolescents in between 16-18 years old. The two studied groups attend the same school and come from similar socioeconomic contexts; however one of the two groups courses the subjects of Contemporary History and Economics (Group A), and the other group doesn't (Group B). The information is collected through a written questionnaire about current news and a discussion group that deals with the subject. The results show the influence of the media on the responses of both groups and a greater feasibility of the solutions proposed by the students of Economics and History.

Keywords: Social representations, crisis and economic problems, critical thinking, creative thinking, problem solving.

(Fecha de recepción: diciembre, 2016, y de aceptación: junio, 2017)

DOI: $10.7203 / \mathrm{DCES} .32 .9394$

* Este artículo se inscribe en la investigación doctoral sobre las representaciones sociales del alumnado sobre la crisis económica, dentro del marco del Programa de Doctorado en Educación de la Universidad Autónoma de Barcelona. 


\section{Introducción}

La crisis económica ha sido, y es, un tema que ha monopolizado, y monopoliza, la actualidad en los últimos años. Todos los poderes desde el primero hasta el quinto han abordado su relación con el fenómeno: las políticas de los gobiernos del mundo se han decantado por programas de austeridad económica y reducción de la deuda, los parlamentos han legislado en favor de un mayor control de los mercados y desde la justicia se ha planteado de forma laxa las responsabilidades de los agentes económicos, mientras que los medios de comunicación han dado la mayor cobertura posible, a la par que los movimientos ciudadanos encontraban en internet el canal de crítica, organización y acción.

La crisis aún es un concepto abierto por definir y comprender en su totalidad y sobre el que no se tiene un juicio nítido ni una solución, por este motivo todos estos canales y discursos sobre la realidad económica nutren las representaciones sociales de los ciudadanos.

Para indagar los conocimientos que tiene el alumnado de bachillerato utilizamos el término representación de Moscovici (1961). Las representaciones sociales son el conjunto de nociones, informaciones, comunicaciones con los otros que recibe el individuo y le ayudan a conformarse una explicación estable de su realidad. No debemos identificarlas con un saber científico y ortodoxo, sino como las muletas que nos permiten comprender nuestro entorno y sus cambios.
En nuestra investigación constituyen una herramienta conceptual para comprender los problemas que desbordan una ciencia social concreta, aquellos que se encuentran en un punto de intersección imbricado, como es nuestro objeto de estudio, en cuanto que engloba la dimensión histórica, social, económica, psicológica y cultural. El alumnado, y podemos extenderlo a la ciudadanía, no cuenta con los conocimientos económicos ni políticos para explicar la crisis económica, pero sí con una amalgama de ideas, que le permiten dar cuenta de su realidad.

Desde la psicología social Jodelet (1984) define las representaciones sociales del siguiente modo:

En tanto que fenómenos, las representaciones sociales se presentan bajo formas variadas, más o menos complejas. Imágenes que condensan un conjunto de significados; sistemas de referencia que nos permiten interpretar lo que nos sucede, e incluso, dar un sentido a lo inesperado; categorías que sirven para clasificar las circunstancias, los fenómenos y a los individuos con quienes tenemos algo que ver; teorías que permiten establecer hechos sobre ellos. Y a menudo, cuando se les comprende dentro de la realidad concreta de nuestra vida social, las representaciones sociales son todo ello junto.

(...) Lo social interviene ahí de varias maneras: a través del contexto concreto en que se sitúan los individuos 
y los grupos; a través de la comunicación que se establece entre ellos; a través de los marcos de aprehensión que proporciona su bagaje cultural; a través de los códigos, valores e ideologías relacionados con las posiciones $y$ pertenencias sociales específicas. (Jodelet, p.473)

Las representaciones sociales son las coordenadas necesarias que ayudan, no sólo a dar sentido al exterior, sino a los individuos a situarse en relación con los acontecimientos estructurales y en especial ante los nuevos escenarios. Con la crisis son muchos los aspectos que cambian, y las preguntas que se formulan: ¿Por qué han perdido el trabajo sus padres? ¿Por qué han desahuciado a los vecinos de arriba? ¿Qué son aquellas manifestaciones de la calle, qué demanda la gente? ¿Por qué cada vez somos más alumnos en clase y este año no me han dado beca?

Los adolescentes no viven en una burbuja aislados del mundo, también son receptores de lo que ocurre en él y de sus consecuencias, como ocurre en este caso concreto de la crisis económica y de sus repercusiones más cercanas. Por ello necesitan conformarse una representación del problema, de un problema global como la crisis económica, comprender sus causas y valorar las consecuencias más cercanas. Comparten un conocimiento común sobre dicha representación de la crisis, pero en este trabajo pretendemos captar sus opiniones e imágenes concretas sobre el fenómeno socioeconómico.

\section{El marco teórico}

Las investigaciones educativas que han profundizado en la enseñanza y el aprendizaje de la economía se remontan a la década de los años 70 y principios de los 80 (Delval et. al., 1971; Jahoda, 1979, 1981; Furth, 1980; Berti y Bombi, 1981; Ng 1982), centrándose en las representaciones económicas de los niños y niñas. Los temas estudiados giran en torno a aspectos cercanos a las primeras etapas de los niños y niñas: de qué vive el tendero de la tienda de juguetes, quién le trae los juguetes, a cuánto los compra y a cuánto los ha de vender... hasta cuestiones más complejas en adolescentes relacionadas con la emisión del dinero, el papel del Estado en la economía o el funcionamiento financiero de los bancos.

Los estudios coinciden en que únicamente a partir de los 12-13 años los jóvenes son capaces de explicar los flujos del dinero, cómo se vende y se obtiene beneficio, por qué se vuelve a comprar más mercancías... pero en general se trata de ideas muy sencillas. $\mathrm{Si}$ incluimos situaciones como pedir un préstamo para financiar un negocio, esperar que nuestras ganancias nos permitan amortizar los gastos del préstamo (ir pagando los intereses) y otros inputs (luz, sueldos, alquiler., etc.)... se encontrarán desbordados, más bien superados, por una cuestión evolutiva: su estadio cognitivo. Aún no dominan plenamente las operaciones formales y los problemas complejos 
La adquisición de las capacidades y competencias económicas no se debe únicamente a los ritmos evolutivos. Las investigaciones también valoran la influencia del contexto y de la enseñanza recibida. El imaginario y el conocimiento de los conceptos económicos no es el mismo si el sujeto ha crecido en un ambiente rural, dominado por las actividades económicas del sector primario, que en un medio urbano, con preponderancia de las actividades terciarias y financieras (Ng 1985; Wong, 1989; Denegri, Etchebarne y Martínez, 2007).

En trabajos recientes Delval y Kohen (2010) destacan que la complejidad de los asuntos económicos se debe a su propia naturaleza multifactorial y el gran número de variables que exigen para su comprensión:

(...) los problemas económicos son fundamentalmente problemas relacionales que implican a multitud de factores. La capacidad para considerar diferentes factores en sus interpretaciones se desarrolla con la edad y con el entrenamiento $y$, aunque supongamos que los adultos la tienen, podemos afirmar que en los niños y adolescentes no está presente antes de los 15 o 16 años. Pensar de una manera relacional es una habilidad que se consigue tarde y con un entrenamiento y ahí la escuela desempeña un papel fundamental. (Delval y Kohen, p.46)

La crisis económica no se explica a partir de una única causa, ni sus soluciones son unívocas ni universales, exigen poder imaginar los diferentes supuestos históricos-políticoseconómicos y un grado de abstracción sofisticado para elaborar operaciones hipotético-deductivas sobre estos futuribles. Desde estos presupuestos cognitivos del alumnado y la naturaleza de los problemas económicos, encontramos propuestas coherentes para el trabajo de la crisis en el aula (González y Pagès, 2010; Nomen, 2010; Santisteban, 2013; Martínez, 2016).

Estas propuestas y orientaciones didácticas intentan acercar la comprensión de la crisis a los adolescentes, pero no olvidemos que se trata de un fenómeno reciente y las investigaciones sobre la enseñanza y aprendizaje de las crisis económicas se encuentran en una fase embrionaria. De modo que nuestro estudio puede considerarse un precedente.

\section{Metodología}

Se realizó un estudio de caso sobre dos grupos de adolescentes de 16-18 años. El primero formado por 35 alumnos recibió clases de Historia Contemporánea y Economía donde se trabajaron los conceptos económicos y se estudió las crisis económicas de 1873 y 1929 (grupo A). Esta fue la principal diferencia respecto al otro grupo integrado por 33 alumnos (grupo B).

Los chicos y chicas son estudiantes del IES Bernat de Sarrià de Benidorm. Benidorm es una ciudad mediterránea, 
perteneciente a la provincia de Alicante, que centra su economía en el turismo y el sector terciario. Como otras ciudades del litoral vivió antes del 2008 un periodo de esplendor económico cimentado en la construcción, burbuja inmobiliaria que se desvaneció, conduciendo al desempleo a aquellos trabajadores y trabajadoras dependientes del sector inmobiliario.

Los instrumentos utilizados en esta investigación fueron el cuestionario, las pruebas escritas y el grupo de discusión. En el cuestionario, seleccionamos cuatro noticias que ilustraban las consecuencias de la crisis económica en distintos ámbitos y contextos (Anexo I) ${ }^{1}$ : a) una familia que sufría un desahucio, b) una profesora que era despedida y tras no encontrar trabajo recurría a un comedor social, c) unos ancianos que eran estafados por un banco y no podían recuperar sus ahorros y, finalmente, d) la situación de miles de jóvenes con estudios universitarios españoles que se ven obligados a emigrar al exterior a buscar trabajo.

Sobre cada noticia les preguntábamos:

1. ¿De qué problema trata este texto? ¿Crees que es un problema importante para los que lo viven? ¿Por qué? ¿Conoces alguna per- sona que haya vivido una situación parecida? ¿Quién? ¿Cómo se resolvió?

2. ¿Es una causa o consecuencia de la crisis? Explica por qué.

3. ¿Crees que te podría pasar a ti o a tu familia? ¿Por qué?

4. ¿Te parece una situación justa o injusta? ¿Por qué?

5. ¿Qué propones tú para solucionar el problema de la noticia?

6. ¿Cómo te llegan las informaciones sobre situaciones o casos similares a los que has leído?

De esta forma pretendíamos averiguar, en primer lugar, si comprendían el problema económico de la noticia y su repercusión social. Además, si sus familiares o conocidos habían vivido situaciones similares nos permitiría conocer cómo lo vivieron ${ }^{2}$ y si valoraron su conocimiento para proponer una solución desde su experiencia. Por el contrario, si no habían vivido o no tenían noticias de experiencias directas podríamos otorgar mayor peso en la proposición de las soluciones a los medios de comunicación o a las clases que recibían en el aula. Sin duda, esta quinta pregunta, era la más importante de todas ellas, para nuestro posterior análisis, de modo que sus respuestas/soluciones a los dramas de cada noticia fueron las que valoramos

\footnotetext{
${ }^{1}$ Pueden consultarse las noticias en: https://anexoscrisis.wikispaces.com/ANEXO+1

2 Previamente les dimos la opción de responder ante las preguntas personales que les resultaran incomodas: "no la quiero responder." Finalmente en ningún caso evadieron ninguna pregunta, contestándolas todas.
} 
principalmente. El análisis de los datos fue cualitativo ya que quisimos captar y profundizar en las especificidades de sus propuestas y alternativas a los problemas.

Las pruebas escritas (Anexo II) ${ }^{3}$, nos permitieron relacionar, a través de las fuentes históricas, la crisis de 1873 y 1929 con la actualidad. Primero se les demanda:

1. ¿Qué similitudes y diferencias podemos establecer entre la crisis de 1873 y la actual?

2. Explica la crisis de 1929, sus causas, consecuencias y políticas adoptadas. Haz referencia a la crisis actual, similitudes, diferencias...

Posteriormente, se les pregunta por el papel de los bancos en ambas crisis, a partir de una caricatura de unos banqueros lanzándose desde los rascacielos en 1929. Esta caricatura contrasta con otra, en la que aparecen cobrando indemnizaciones millonarias los directivos de entidades que quebraron e incluso fueron rescatadas por el gobierno.

El grupo de discusión integrado por 3 chicos y 3 chicas representativos de la realidad de los grupos. Sus respuestas en los cuestionarios y su relación con la crisis fueron los criterios de su elección. El intercambio de sus opiniones permitió ampliar los problemas tratados en las noticias a otros específicos de la loca- lidad y más cercanos a ellos. Se trataba de indagar la justificación y la argumentación de las soluciones propuestas a los problemas planteados. Sin duda conocer cómo argumentan, qué fuentes, datos estadísticos, testimonios de autoridades... utilizan para corroborar sus opiniones o refutar las otras, constituye la pieza angular del pensamiento crítico (Tamayo, Zona y Loaiza, 2015).

Por último, se trata de una investigación-acción ya que el estudio comparado entre el alumnado que recibió las clases de Economía e Historia Contemporánea y el que no lo hizo, nos permite comprobar la incidencia de las clases en sus aprendizajes sobre la crisis económica.

\section{Resultados}

Presentamos, a continuación, los resultados de los cuestionarios y de las actividades realizadas en la unidad didáctica.

\section{Los resultados de los cuestionarios}

Las respuestas obtenidas en la pregunta número 5 de cada noticia fueron las siguientes:

a) Soluciones sobre los desahucios. En el grafico se muestra como el 59\% optan por prolongar la hipoteca en el tiempo bajando la cuota, aunque haciendo matices del estilo siguiente: "si el banco se va a quedar la casa y la tendrá vacía,

${ }^{3}$ Las pruebas que realizaron se encuentran en https://anexoscrisis.wikispaces.com/ANEXO+2 
que más le da que estén unos inquilinos o esta familia aunque le pagan un poco menos" (Ramón, 17 años, grupo A) y críticos "que no den hipotecas a gente que saben que no puede pagarlas o le ofrezcan una más asequible" (Julia, 16 años, grupo B), e indignados "no puedo entender cómo después de pagar durante años cuotas, y una vez se la quitan, todavía tienen que pagar al banco cuando ya no viven allî" (Mónica, 17 años, grupo B).

Esta última alumna, optaría por prolongar una hipoteca viable, asequible a los recursos de los desahuciados. Su reflexión, su incomprensión de la injusticia, le lleva a argumentar como quienes defienden la dación en pago. Otro alumno, sí que plantea la dación en pago como medida de inicio "entregar la casa a cambio de liquidar la deuda (...) lo que hacen en Madrid o Barcelona, negociar con los bancos por esta indecencia" (Fran, 16 años, grupo A).
Un $8 \%$ presenta una solución parecida: facilitar una vivienda barata que puedan pagar o un alquiler social.

Únicamente recurren a los políticos el 5\%: "solucionarlo con los políticos y un gobierno nuevo" (Pepa, 18 años, grupo B) que en un caso es continuista "que continúe el actual gobierno, que lo está haciendo bien" (José, 17 años, grupo B). Y un alumno cae en una tautología "primero salir de la crisis para evitar estos problemas" (Roque, 18 años, grupo A). Un $25 \%$ del alumnado no propone ninguna solución, la deja en blanco (7\%) o responde "no sé" (18\%).

Hemos dejado para el final las soluciones superficiales, que responden directamente, sin conocimiento de causa. Corresponden a dos alumnos (3\%): "que les den una vivienda" (Laura, 17) y "que den casas, que aunque no sean muy grandes, puedan vivir bajo un techo digno" (Almudena, 18).

\section{Gráfico I. Soluciones a los desahucios.}

Fuente: elaboración propia

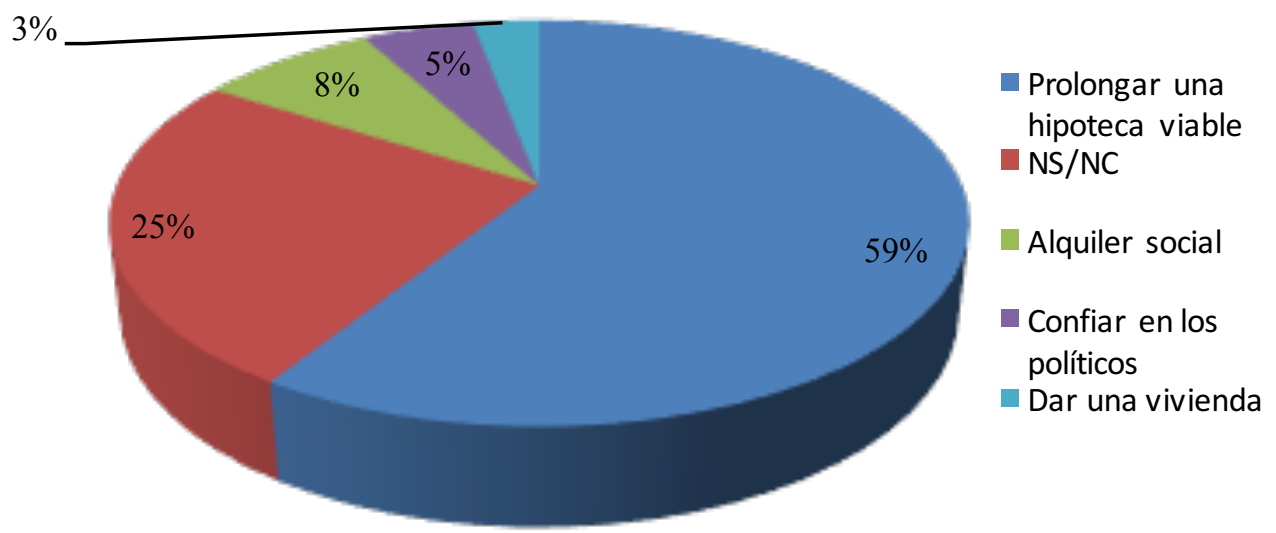


b) Ante la pauperización de las clases medias y la pérdida de trabajo. Responden "crear trabajo" 13 alumnos (19\%). Muchos de los padres y las madres de estos alumnos han cambiado de trabajo durante la crisis.

Es la "solución” aportada por más alumnos, junto con cambiar la mentalidad de las empresas (15\%): "que recursos humanos de las empresas se fijen en la experiencia, el currículum y no en la edad de los trabajadores y de las trabajadoras" (Gloria, 16 años, grupo A).

Hemos considerado que las otras respuestas son:

1) de estímulo económico y estructurales (7\%): "subvencionar a las empresas para que contraten a gente" (Luis, 18 años; grupo A), "hacer un plan de reinserción laboral de la gente mayor" (Irina, 16 años; grupo A), "avanzar la edad de jubilación, pero claro con lo que han robado los políticos es difícil" (Judith, 16 años; grupo A), "dar créditos a empresas con dificultades para que no cierren o facilidades para que contraten a más gente" (María, 17 años; grupo A).

2) De ayuda a las personas paradas (15\%): "que cobren el paro hasta que convoquen plazas" (Manu, 17 años, grupo A), "prolongar el paro" (Mohamed, 17 años, grupo B) . Dentro de este bloque, algunas respuestas son muy superficiales ya que no afrontan el problema, como "hacer más comedores sociales" (7\%), "que reciban la ayuda de la iglesia y las ONG” (Sebastián, 17 años, grupo B) o "bajar el precio de los productos básicos, aceite, pan" (Ernesto, 16 años, grupo B).

Un alumno no ve un problema en la noticia o lo ve solucionado con los comedores sociales y la caridad "no es un problema ya pagamos a gente para que les ayude en los comedores sociales" (Yosef, 17 años, grupo B). También encontramos los que no hacen ninguna propuesta (42\%): porque la dejan en blanco $(16 \%)$ o responden "no sé" $(26 \%)$.

\section{Gráfico II. Soluciones a la pauperización y desempleo.}

Fuente: elaboración propia

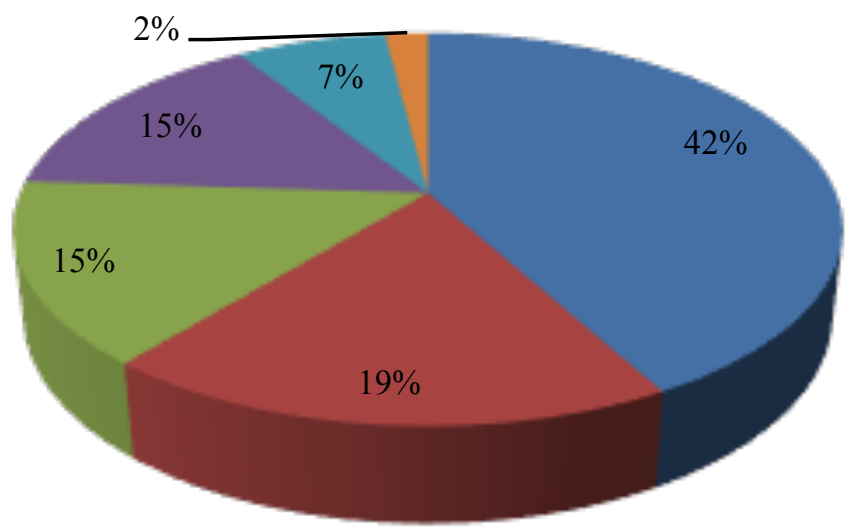

NS/NC

Crear trabajo

- Valorar la experiencia

Ayudar a los parados

De estímulo económico 
c) La estafa bancaria (participaciones preferentes).

Tal como reproducimos en el gráfico, el $16 \%$ del alumnado opta por devolver el dinero a los legítimos propietarios y una alumna recurre a la máquina de hacer dinero, "hacer dinero es sólo darle a un botón, no creo que sea tan difícil devolver a cada cual lo suyo" (Eva, 17 años; grupo B). Condenar a los culpables, "meterlos en la prisión", es la medida que tomarían 4 alumnos (6\%) que sólo castigan al infractor pero olvidan a las víctimas.

Las propuestas que van más allá de reparar los casos individuales y pretenden establecer un marco que evite futuras estafas similares, computan el $31 \%$ : pretenden conseguir "purificar las entidades bancarias de gente desalmada, pero esto no pasará, puesto que hace falta un gobierno nuevo que se preocupe por la gente y no por rescatar a los bancos" (Joaquín, 16 años; grupo B), "que los bancos tengan más transparencia y los usuarios sepan qué están haciendo con sus ahorros" (Iñaki, 17 años; grupo A), "controlar a los bancos e informarse bien los clientes", especificando 2 de estos que no confían en los bancos ni supervisores adláteres "que no sea la gente del banco, sino asesores neutrales del gobierno los que informen y estén presentes a la hora de firmar" (Carmen, 17 años, grupo A)

Un $47 \%$ de alumnos y alumnas dejan la respuesta en blanco (19\%) o marcan "no sé" (28\%). Un número superior al de la segunda noticia.

\title{
Gráfico III. Soluciones a las preferentes.
}

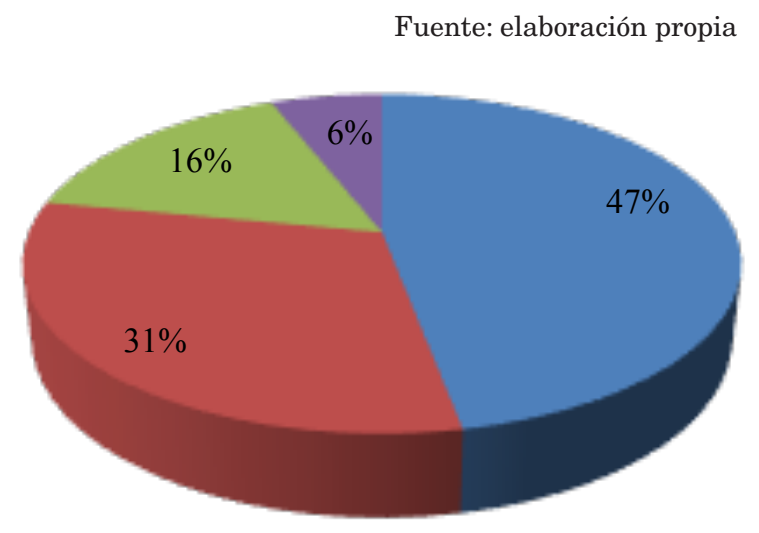

\author{
NS/NC \\ Corregir el \\ sistema \\ Devolver el \\ dinero \\ - Castigar a \\ los culpables
}

d) Éxodo universitario.

41 alumnos y alumnas (60\%) no proponen soluciones: 24 (35\%) marcan "no sé” y 17 (25\%) dejan la respuesta en blanco.
La propuesta mayoritaria (29\%) no va más allá de las buenas intenciones y no contempla el problema a largo plazo, puesto que se limita a contratar a los jóvenes, "dar más trabajo" y en un caso 
aislado "dar trabajo primero a los de aquí".

Un 7\% opta por una solución global, pero vacía, al ser más un deseo que medidas para conseguir un objetivo o al menos mitigar la fuga de cerebros: "erradicar la crisis", "salir de la crisis", "acabar con la crisis"... Sólo una respuesta es coherente ya que tiene en cuenta más factores y ve más las consecuencias para prevenirlas: "contratos de prácticas para los jóvenes que salen de la universidad, pero en condiciones dignas" (Remedios, 17, grupo B) y otro alumno no aporta ninguna medida, porque "no veo ningún problema es un acto de supervivencia” (Ignacio, 16, grupo A).

\section{Gráfico IV. Soluciones al éxodo universitario}

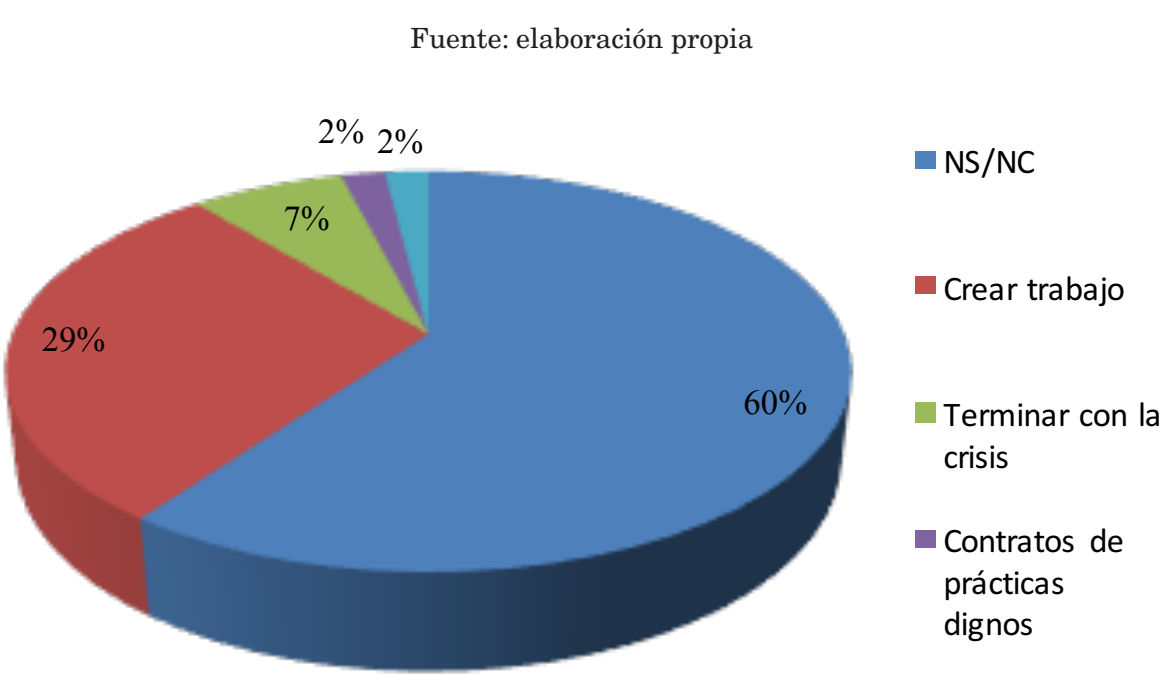

Las actividades de las unidades didácticas (pruebas escritas)

Las pruebas escritas sólo fueron realizadas por el alumnado que acudía a las clases de Historia Contemporánea. Más del 95\% relacionan la sobreproducción industrial de 1873 con la burbuja de la construcción. Este texto es un ejemplo de las respuestas más frecuentes: "había gran cantidad de fábricas produciendo lo que condujo al excedente (...) se asemeja a hoy en día con tantas casas construidas" (Jorge, 17, grupo A). También un poco más del $85 \%$ compara la emigración europea a las colonias con el éxodo hacia Europa para encontrar trabajo. Todos identifican el paro como un síntoma común en las dos crisis. Tres alumnos ven un mismo comportamiento: "el capitalismo es la codicia por obtener más antes y también ahora, lo que nos lleva a las crisis" (Pepe, 16, grupo A) , "los mercados continúan buscando 
otros mercados, antes eran materias primeras y ahora con la globalización las multinacionales explotan a la gente para obtener el máximo de beneficios, como hace Zara" (Judith, 16 años, grupo A), "los empresarios buscaron controlar el mundo y sus recursos, produjeron más y más, sin darse cuenta que la oferta sería mayor que la demanda" (Dimas, 17, grupo A). Dos alumnos lo relacionan con los discursos darwinistas. Este texto pertenece a uno de ellos: "el pensamiento darwinista también se podría aplicar hoy en día. Cada vez nos meten más obstáculos para llegar a nuestras metas y así van eliminando gente. Si no tienes dinero, que es lo que mueve todo, lo tienes mucho más difícil" (Manolo 16 años grupo A).

Las actividades realizadas por el alumnado en la unidad didáctica que relaciona las crisis de 1929 y 2008, nos muestran los siguientes resultados: más del $95 \%$ comparan la crisis inmobiliaria con la subida de los valores de la Bolsa; y el crac de 1929, el Jueves Negro, con la caída de precios de las propiedades "compraban ciegamente las acciones esperando que subieran (...) creían que los precios de las casas siempre subirían, así si no podías pagar, el banco se quedaba la casa revalorizada" (Ezequiel, 16 años, grupo A). El paro también es señalado por todos como la principal consecuencia: "mucha gente fue a la calle, cerraron las empresas, no tenían para comer y salían a la calle con carteles pidiendo trabajo...en 2008 mucha gente de clase media ha acabado en la indigencia" (Iñaki, 16 años, grupo A).
Casi la mitad $(42,8 \%)$ comparan el New Deal con el Plan E durante el gobierno de Zapatero ("el New Deal ayudó a salir de la crisis y en 2008 el Plan E dio trabajo a gente parada haciendo obras públicas" (Nieves, 16 años, grupo A), y en contraposición a los recortes "Roosevelt aplicó políticas keynesianas, promovió el New Deal, el Estado incentivó la economía dando subvenciones a las empresas y aumentando el sueldo a los trabajadores, al contrario que en España que cada día los salarios son más reducidos (Rafael, 16, grupo A)."

En las dos imágenes sobre el papel de la banca, en las que se comparaba la actitud de los banqueros en 1929 y su impunidad en 2008, responden haciendo una reconstrucción cronológica, contextualizándolas y explicando las diferentes actitudes. En todas las explicaciones que dan, la secuencia temporal de los hechos, su relato es acertado: “en aquella situación de pánico muchos banqueros se suicidaron, les superaba la situación, al verse arruinados; en cambio ahora, cobran indemnizaciones y se mantienen indiferentes con los problemas de los ciudadanos (desahucios, paro, pobreza...)".

\section{Los resultados del grupo de discusión}

En el grupo de discusión emergieron temas relacionados con las noticias, que ahora vincularon con sus experiencias familiares. El desempleo, tema de la primera noticia, era una cuestión importante para los alumnos que durante el periodo de la crisis habían 
visto cómo su padre o su madre perdían sus empleos. Un alumno se centró en la crisis inmobiliaria, su padre era ebanista y perdió el trabajo a la par que decaía la demanda de trabajos de albañiles, electricistas, pintores, capataces de obra, etc. Su testimonio demuestra la evolución laboral de su padre paralela a la crisis local: "El problema es que en la economía española, sólo tenemos la construcción. Habría que invertir en exportaciones. Hay que mirar otros sectores (...) Mi padre era carpintero y ahora se dedica a la seguridad" (Luis, 18 años, grupo A).

Otra alumna vio a su madre desempeñar varios trabajos en poco tiempo, realizando contratos breves, generando inestabilidad en la familia y continuo desasosiego. No propone una solución concreta, pero cree que los perjudicados y beneficiados son siempre los mismos, es en esta bipolaridad donde se encuentra el problema y en la que deben actuar las posibles soluciones: "Con la crisis, los directores de empresas y hoteles se aprovechan de la gente, explotando a los trabajadores. Es muy injusto" (Silvia, 17 años, grupo B).

Los progenitores de los alumnos se encuentran entre los 45-55 años, lo que les convierte en un colectivo con dificultades para encontrar trabajo. Los miembros del grupo de discusión se identifican con la protagonista de la segunda noticia que pierde su trabajo: "a esa edad es difícil que te contraten" (Ramón, 16 años, grupo B), "las empresas se fijan en la edad a la hora de contratarte y no en la valía. Mi madre ha estado muchos periodos sin trabajar (Gloria, 16 años, grupo A)".

Sólo dos alumnos de los seis ven el problema y la solución en los políticos y sus decisiones: "Combatir el fraude fiscal. El $25 \%$ de nuestra economía es sumergida" (Fran, 16 años, grupo A), "la solución es bajar los sueldos de los políticos. Es inmoral cuando los sueldos mínimos son ridículos, las condiciones precarias, contratos temporales, etc. (...) Las cuentas de dinero malversado en Suiza, los casos de corrupción y malversación de los políticos tienen la partida presupuestaria de sanidad, pero después quieren austeridad" (Luis, 18 años, grupo A).

La mayoría del alumnado entiende que la solución está en sus actitudes individuales: "tengo un conocido que trabajaba en una central nuclear y se tuvo que ir a Japón y gana mucho más dinero que aquí" (Silvia, 17 años, grupo B), "tengo un primo que no tiene estudios y está trabajando en Londres en una cafetería" (Gloria, 16 años, grupo A) ... por lo tanto he de "estudiar y prepararme, posiblemente terminaré trabajando fuera (...) porque Benidorm se basa en el turismo y la mayoría del trabajo que hay aquí son cafeterías y hoteles, si quieres trabajar en lo que te gusta (...) aquí no encontrarás de lo que has estudiado" (Luis, 18 años, grupo A), "conozco gente que dejó los estudios y ahora vuelve al Bachillerato nocturno. Muchos abandonan los estudios para trabajar en verano, pero vuelven cuando ven que no les renuevan los contratos más allá del verano" (Silvia, 17 años, grupo B). 


\section{Análisis y discusión de los resultados}

El problema planteado en la primera noticia sobre los desahucios, es el que mejor resuelven en conjunto, pues sólo un $25 \%$ no es capaz de ofrecer una alternativa. En las noticias $2(42,6 \%), 3$ $(47 \%)$ y $4(60,2 \%)$, el porcentaje prácticamente se duplica.

Además no es una cuestión únicamente de número, de cantidad, sino cualitativa, más del $67 \%$ de las medidas contra los embargos son viables y tienen en cuenta múltiples variables y a las dos partes (desahuciado y banco). Como señalan Delval y Kohen (2010), contemplan la complejidad relacional de los problemas económicos. Ofrecen una hipoteca menor, que permita seguir pagando y de este modo ajustar la cuota a la coyuntura actual, frente a las circunstancias en que se firmó la hipoteca, de este modo podrían pagar y el acreedor cobrar.

Algunas llegan a ir más allá de la ley -legal y justo no son sinónimos- y consideran que las mensualidades pagadas más el valor de la casa, es superior al precio de la vivienda en el mercado inmobiliario actual. Recordemos que la dación en pago encuentra muchas dificultades en nuestro sistema jurídico.

Sólo un 5\% son respuestas unívocas que no contemplan otros factores, se limitan a cambiar el verbo contrario o introducir un "no": si desahucian, la solución es no desahuciar o dar viviendas.

En las otras noticias aumentan este tipo de razonamientos. Ante el paro, que es la causa del problema de las noticias 2 y 4, proponen "crear empleo", pero sin valorar, sin relacionarlo con otros problemas como la capacidad de inversión del Estado, el cierre de empresas o la falta de consumo de los ciudadanos.

De igual modo, ante el empobrecimiento de las clases medias o la estafa económica, algunos recurren a "crear dinero". Son un ejemplo de la ausencia del pensamiento relacional, ya que no estiman las consecuencias inflacionarias de una política monetaria expansiva, ni las limitaciones de los gobiernos europeos, pues el órgano competente en este asunto el Banco Central Europeo.

La tentación de la máquina del dinero irresponsable o de crear trabajo desde la nada, están presentes desde las edades tempranas:

(...)mientras que los más pequeños señalan que cualquiera que disponga de la máquina adecuada puede poner una fábrica de dinero, poco a poco van descubriendo que las fábricas de dinero no son como las demás $y$ que las decisiones sobre quién y cuánto dinero se fabrica depende de instituciones sometidas al poder político, como es el Banco de España. (Del Val y Kohen. 2010, p.46-47)

Este tipo de respuestas son expuestas por el alumnado del grupo B, que no recibe las clases de Economía. Contrasta con el alumnado del grupo A que justifica sus respuestas basándose en el flujo circular de la renta, así en la noticia 2 , proponían medidas de estímulo 
económico o destinar ayudas a los parados, pero no únicamente como un subsidio temporal para sobrevivir, sino como un punto de arranque para retroalimentar el flujo de la renta. Cabe destacar que esta serie de razonamientos, los justifican mediante el flujo circular de la renta: "si gente parada recupera el empleo, el Estado dejará de abonarles el subsidio y reducirá la deuda" (Jaime, 16 años, grupo A), "la gente que encuentra empleo, consume los productos de los negocios" (Vega, 16 años, grupo A), "es necesario invertir para activar la economía" (Luis, 18 años, grupo A), etc. $\mathrm{E}$ incluso algunos relacionan desde este enfoque holístico los problemas de varias noticias: "si no pueden retirar su dinero del banco, no pueden pagar hipotecas y otros gastos, pueden acabar desahuciados" (Tania, 16 años, grupo B)

La siguiente imagen se encuentra en su libro de Economía de $1^{\circ}$ de Bachillerato (Imagen I). Asignatura que no cursan hasta esta etapa, por lo tanto parece más que probable la incidencia de las clases en sus conocimientos y la aplicación de los mismos en los problemas económicos actuales. Las explicaciones que arguyen, siguen la concatenación de ideas como en el dibujo explicativo, que encuentran en su manual utilizado a lo largo del curso académico.

\section{Imagen I. Diagrama del flujo circular de la actividad macroeconómica en el libro de texto de Economía de los estudiantes}

Fuente: Economia $1^{\circ}$ Bachillerato (Gimeno, et al., 2008, p.143)

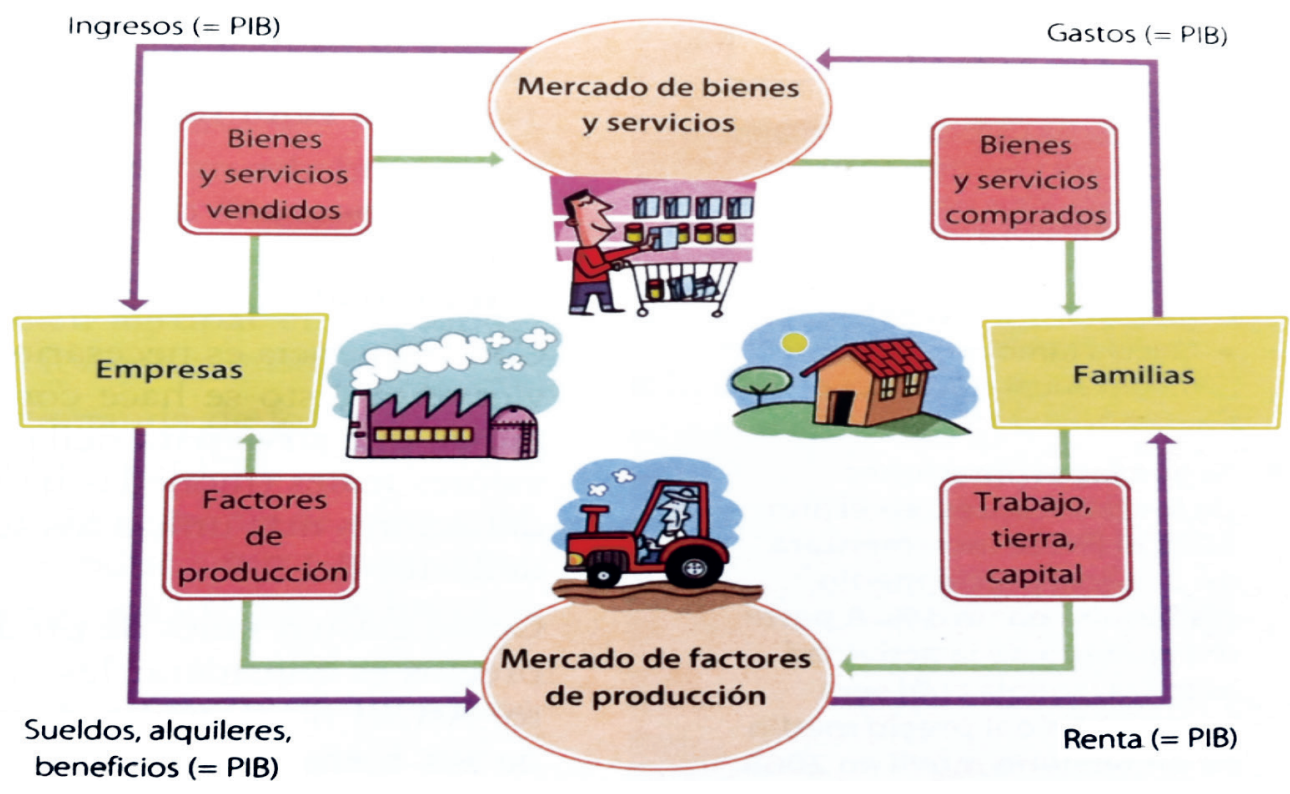


No sólo observamos en sus soluciones (grupo A) una mayor dimensión económica e histórica de los problemas, planteando la repercusión de las medidas, frente al reduccionismo del otro grupo, sino también el empleo y dominio de conceptos propios de la disciplina económica, que lógicamente demuestran la visibilidad de aspectos o complejidades que no son estimados en las respuestas de los otros chicos y chicas. En este segundo grupo, buscan soluciones coyunturales, instantáneas -como cambiar el gobierno, dar casas, dar trabajo- pero no estructurales ni a largo plazo.

También en el grupo focal, justifican sus intervenciones en la misma línea: "Incentivar el pequeño comercio y aumentar los impuestos a grandes empresas y multinacionales, porque en verdad, el motor son las pequeñas empresas y son las que la crisis la sufren más (...) para hacer más contratos tendríamos que inyectar más dinero a las empresas, porque la economía irá mejor y así la economía se podrá mover algo, si la gente no cobra más, la economía no se mueve" (Luis, 18 años, grupo A).

Este mismo razonamiento lo aplican para comprender las crisis de 1873 y 1929. Las variables de la oferta y la demanda, las utilizan para explicar la sobreproducción de 1873 y el aumento del precio de las acciones en 1929. La especulación bursátil la comparan con el boom inmobiliario, del que son perfectamente conocedores, pues observan los esqueletos de edificios y obras públicas que se paralizaron con la crisis.
El aspecto más importante son sus reconstrucciones históricas y cómo consiguen dotar de verosimilitud y coherencia sus narraciones tanto del pasado como del presente. Como señala Santisteban (2010) pasado y presente se nutren en un diálogo en el que el alumnado adquiere a través de la imaginación histórica -con rigor y fundamentada en las fuentes- la competencia crítica y creativa:

El uso de la imaginación histórica no pretende ofrecer una imagen completa o perfecta del pasado, sino dotar de sentido a los acontecimientos históricos, a través de la empatía y la contextualización. Por lo tanto, según este autor -Stephane Levesque- podemos viajar en el tiempo con la imaginación histórica, como instrumento útil y necesario del pensamiento histórico como pensamiento creativo, siendo conscientes que lo hacemos desde nuestro contexto cultural y usando el aparato conceptual de la actualidad. (Santisteban, p.46)

Su pensamiento crítico no se limita a comprender las causas y mecanismos que envuelven los procesos económicos, sino que el conocimiento empático, eleva la crítica a la dimensión ética, llevándoles a considerar la propia naturaleza egoísta del capitalismo y de las multinacionales, al explicar "el pensamiento darwinista", "el capitalismo es codicia" o los intereses de Zara.

En el grupo focal veían en la especulación inmobiliaria uno de los agra- 
vantes de la crisis y en los cuestionarios señalaban las responsabilidades políticas por "no poner freno en la concesión de hipotecas" y "los bancos por especular sin importar las consecuencias" e incluso también en los constructores "por saturar el mercado, pensando sólo en su enriquecimiento". En el otro grupo de alumnos se culpa más a los políticos, pero no por sus decisiones, sino por prejuicios personales: "son corruptos", "avariciosos", "sólo piensan en su jubilación”.

Estudiar otras crisis del pasado les permite observar qué decisiones se tomaron, qué consecuencias tuvieron y por lo tanto proyectar los aprendizajes a la actualidad. Esta es la gradación entre el pensamiento crítico y creativo, interpretar situaciones del pasado, experiencias colectivas en otros escenarios con el fin de adquirir competencias para la resolución de problemas actuales (Kemmis, Cole y Suggett, 2007).

Las noticias 2 y 4 relacionadas con el desempleo, son las que se inscriben dentro de un enfoque liberal, el esquema del flujo circular de la economía explica tanto los periodos de bonanza como de crisis. El desequilibrio entre la oferta y la demanda, puede explicar grosso modo todas las crisis y en el caso de las dos noticias, la situación de desempleo prolongado que obliga a recurrir a los comedores sociales y la emigración de jóvenes en busca de trabajo. Por este motivo es en la noticia 2 en la que observamos la distancia entre las propuestas de los estudiantes de Economía frente al resto, ya que recurren a medidas para incentivar el consumo e inversiones para frenar el paro, pero sin contemplar la prima de riesgo o la capacidad de endeudamiento del Estado.

Nos ha sorprendió la abstención en la noticia 4, pensábamos que se identificarían plenamente con su generación, los jóvenes universitarios que sólo tienen unos años más que ellos, antes que con los otros protagonistas de las noticias. De hecho empatizan y son conscientes de las dificultades, pero por su juventud tienen ansias de viajar y conocer mundo y no ven emigrar un problema tan importante como nosotros anticipábamos a priori, más bien es una oportunidad en algunos casos. Además como reflejan sus intervenciones en el grupo focal, debemos añadir un factor local, el alumnado ha interiorizado que la economía de Benidorm no es el ecosistema ideal para encontrar trabajos si tienen una formación universitaria, más bien la oferta laboral se centra en trabajos de baja cualificación profesional, precarios, dependientes de la llegada de turistas en la estación del verano y que les relegan al desempleo como podemos observar en la tabla siguiente. (Tabla 1)

Por otro lado las noticias 1 y 3 , referentes a los desahucios y las acciones preferentes, tratan problemas coyunturales y específicos de esta crisis. Dramas sociales e injusticias de gran cobertura en los medios de comunicación, y cuyas causas y respuestas concretas están más en la actualidad política que en los libros de Historia, aunque podamos transferir lecciones del pasado, desde la crisis de 1929 o más recientemente estafas como el Fórum Filatéli- 
Tabla I. Contratos durante el año 2015

\begin{tabular}{|c|c|c|c|c|}
\hline Mes & Indefinido & Temporal & Indefinidos $\%$ & Temporales\% \\
\hline ENERO & 220 & 2.679 & $7,59 \%$ & $92,41 \%$ \\
\hline FEBRERO & 210 & 2.411 & $8,01 \%$ & $91,99 \%$ \\
\hline MARZO & 295 & 3.872 & $7,08 \%$ & $92,92 \%$ \\
\hline ABRIL & 301 & 4.593 & $6,15 \%$ & $93,85 \%$ \\
\hline MAYO & 307 & 4.194 & $6,82 \%$ & $93,18 \%$ \\
\hline JUNIO & 287 & 5.114 & $5,31 \%$ & $94,69 \%$ \\
\hline JULIO & 252 & 5.119 & $4,69 \%$ & $95,31 \%$ \\
\hline AGOSTO & 221 & 3.376 & $6,14 \%$ & $93,86 \%$ \\
\hline SEPTIEMBRE & 221 & 4.019 & $5,21 \%$ & $94,79 \%$ \\
\hline OCTUBRE & 213 & 3.649 & $5,52 \%$ & $94,48 \%$ \\
\hline NOVIEMBRE & 194 & 2.972 & $6,13 \%$ & $93,87 \%$ \\
\hline DICIEMBRE & 199 & 3.483 & $5,40 \%$ & $94,60 \%$ \\
\hline PROMEDIO & 243 & 3.790 & $6,17 \%$ & $93,8 \%$ \\
\hline
\end{tabular}

Fuente: Anuario Benidorm en cifras (Nuñez de Cela, 2016)

co o Madoff. En consecuencia en estas dos preguntas las propuestas de ambos grupos son más similares y parece que los medios de comunicación, el seguimiento del alumnado de las noticias, tiene mayor influencia que las clases recibidas. La crisis se ha convertido en un tema estrella para los medios de comunicación, pero el gran impacto mediático les "obliga a estar informados", pero un "excesivo" impacto mediá- tico puede llegar a "saturarlos" (Pagès y Sant, 2013, p.215).

\section{Conclusiones}

Las cuestiones económicas exigen realizar operaciones relacionales, manejar múltiples variables, conocimientos matemáticos, pero además introducir factores psicológicos y políticos. Pretender que nuestros alumnos 
aporten soluciones perfectas sería excesivo, cuando gobiernos y economistas se vieron desbordados por la crisis económica y la idoneidad de las medidas no goza de consenso entre los expertos ni aporta los resultados esperados.

Esta dificultad no debe desalentarnos, todo lo contrario, sino responsabilizarnos de la necesidad de introducir en las prácticas de aula los asuntos económicos, como problemas abiertos. Una exigencia plausible por los resultados de nuestra investigación-acción, ya que el alumnado que recibió las clases de Economía e Historia Contemporánea, fue capaz de ofrecer medidas ante los problemas. Es innegable que en un mundo globalizado y dominado por los mercados financieros, la comprensión de los mecanismos económicos es una condición necesaria para formar ciudadanos comprometidos, que superen su papel receptivo y dejen de delegar responsabilidades en sus dirigentes políticos.

De igual modo, en la práctica del aula es indispensable la aportación de los conocimientos económicos, pero no como meros conceptos, sino contextualizados históricamente y en problemas reales, simulados o futuribles, para primero analizar críticamente y posteriormente debatir y argumentar entre todos.

El pensamiento crítico es un paso previo al pensamiento creativo, ya que el pensamiento crítico puede no ser creativo, pero el pensamiento creativo es siempre crítico (Santisteban, 2010, p.46). Para ofrecer alternativas al rumbo de los acontecimientos se necesita imperiosamente analizar y comprender el pro- blema y las decisiones tomadas hasta la fecha, así como las consecuencias originadas. Todo razonamiento creativo encierra una exégesis crítica de la realidad, pero no toda lectura crítica desemboca en una implementación creativa. En los cuestionarios, sus soluciones propuestas son mucho menos generosas respecto a sus críticas. Esta jerarquía dentro del pensamiento social, implica también un ritmo en didáctica de las Ciencias Sociales y en el modo de trabajar las cuestiones socialmente vivas (Legardez, 2003). Las orientaciones de González y Santisteban (2011) son unas magníficas coordenadas para iniciar este periplo didáctico y emancipador:

En primer lugar, es necesario descifrar o decodificar los diversos lenguajes presentes en la sociedad, lo cual nos lleva a interactuar en muchas ocasiones con la competencia matemática, así como con la competencia artística y cultural. En segundo lugar, este pensamiento debe ser crítico, para valorar los hechos, las situaciones o las actitudes de las personas o de los grupos sociales. En tercer lugar, debemos ayudar a desarrollar el pensamiento creativo, para pensar soluciones a los problemas y proponer alternativas. Por último, es necesario argumentar estas alternativas, debatir y defender nuestras opiniones, por lo cual es imprescindible la competencia lingüistica y audiovisual. (González y Santisteban, p.42) 


\section{Referencias bibliográficas}

BERTI, A. E. y BOMBI, A.S. (1981). Il mondo economico nel bambino. Firenza: La nuova Italia.

DELVAL, J. y KOHEN, R. (2010). La crisis en la escuela. Cuadernos de Pedagogía, 405, 44-50.

DELVAL, J.; SOTO, P.; FERNÁNDEZ, T; DEAÑO, A., GONZÁLEZ, E., GIL, P. y CUEVAS, M. M. (1971). Estructura y enlace de los conocimientos científicos: Ciencias sociales. Las nociones de economía y poder. Informe multicopiado. Madrid: Instituto de Ciencias de la Educación.

DENEGRI, M.; ETCHEBARNE, S. y MARTÍNEZ, G. (2007). La comprensión del funcionamiento bancario en adolescentes chilenos: Un estudio de Psicología Económica. Interdisciplinaria , 24 (2), 137-159.

FURTH,H.G.(1980).Theworldofgrownups. Children's conceptions of society. New York: Elsevier North Holland.

GIMENO, R.; ESCOT, L.; OLMEDO, E.; MATEOS, R.; MONTES, J.L.; GRAU, P.; FRANCO, L. y VELASCO, F. (2008). Economia $1^{\circ}$ Bachillerato. Santillana: Madrid.

GONZÁLEZ, N. y SANTISTEBAN, A. (2011). Cómo enseñar ciencias sociales para favorecer el desarrollo de las competencias básicas. Aula de Innovación Educativa, 198, 41-47.

GONZÁLEZ, N. y PAGÈS, J. (2010). ¿Por qué y qué enseñar sobre la crisis? Cuadernos de Pedagogía, 405, 52-60.
JAHODA, G. (1979). The construction of economic reality by some Glaswegian children. European Journal of Social Psicology, 19, 115-127. DOI: 10.1002/ejsp.2420090202.

JAHODA, G. (1981). The development of thinking about economic institutions: The bank. Cahiers de Psychologie Cognitive, 1(I), 55-73.

JODELET, D. (1986). La representación social: fenómenos, concepto y teoría. En S. MOSCOVICI, Psicologia Social (469-494). Barcelona: Paidós.

KEMMIS, S.; COLE, P. y SUGGETT, D. (2007). Hacia una escuela socialmente crítica. Orientaciones para el currículo y la transición. Valencia: Nau Llibres.

LEGARDEZ, A. (2003). L'enseignement des questions sociales et historiques, socialment vives. Le Cartable de Clio, 3, 245-253.

MARTÍNEZ, A. (2016). Entender la crisis, desnaturalizar el capitalismo. Íber. Didáctica de las Ciencias Sociales, Geografía e Historia, 84, 14-24.

MOSCOVICI, S. (1961). La Psychanalyse, son image et son públic. Paris: PUF. NG, S.H. (1982). Children's ideas about the bank and shop profit: Developmental stages and influences of cognitive contrast and conflict. Journal of Economic Psychology, 4, 209-221. DOI: 10.1016/0167-4870(83)90027-2.

NG, S.H. (1985). Children's ideas about the bank: A New Zealand replication. European Journal of Social 
Psychology, 15, 121-123. DOI: 10.1002/ ejsp.2420150109.

NOMEN, J. (2010). Una cuestión viva y compleja. Cuadernos de Pedagogía, 405, 64-67.

NUÑEZ DE CELA, J.A. (2016). Anuario Benidorm en cifras. Benidorm: Ayuntamiento de Benidorm. Recuperado de http://benidorm.org/sites/default/files/ documentos/benidorm_en_cifras_2016 web.pdf (8 de diciembre de 2016)

PAGÈS, J. y SANT, E. (2013). La influencia de los medios de comunicación en la socialización política de los jóvenes de 12-16 años en un contexto de crisis económica. En J.J. DÍAZ MATARRANZ; A. SANTISTEBAN; A. CASCAJERO (Eds.). Medios de comunicación y pensamiento crítico. Nuevas formas de interacción social (207-216). Alcalá de Henares: Universidad de Alcalá.
SANTISTEBAN, A. (2010). La formación de competencias de pensamiento histórico. Clío \& asociados: La historia enseñada, 14, 34-56. DOI: 10.14409/ cya.vli14.1674.

SANTISTEBAN, A. (2013). La alfabetización económica de la ciudadanía. Uno. Revista de Didáctica de las Matemáticas, 62, 21-30.

TAMAYO, O. E., ZONA, R., y LOAIZA, Y.E. (2015). El pensamiento crítico en la educación. Algunas categorías centrales en su estudio. Revista Latinoamericana de Estudios Educativos, 11(2), 111-133.

WONG, M.H. (1989). Children's acquisition of economic knowledge. Understanding banking in Hong Kong and the USA. En J. VALSINER (Ed.). Child development in cultural context. Norwood, NJ: Ablex. 